\title{
La concepción mesiánica del lenguaje de Walter Benjamín.
}

\section{The messianic conception of Walter Benjamín's language.}

\author{
Jesús López Salas \\ Departamento de Filosofía / Universidad de Guadalajara (MÉXICO) \\ CE: jlsalasqt@gmail.com ID ORCID: 0000-0002-0865-6499
}

DOI: $10.32870 /$ sincronia.axxiii.n76.1b19

Esta obra está bajo una Licencia Creative Commons Atribución-NoComercial 4.0 Internacional

Recibido: 09/01/2019

Revisado: $21 / 02 / 2019$

Aprobado: 03/04/2019

\section{RESUMEN}

El texto explora la concepción del lenguaje de Benjamín centrándose en su noción del nombre, muestra su origen teológico y sus repercusiones epistemológicas y ontológicas. Se muestra la relación del pensamiento concreto frente al pensamiento abstracto.

Palabras clave: Nombre. Pecado original. Revelación. Traducción. Juicio. Benjamín.

\section{ABSTRACT}

The text explores the conception of Benjamín's language focusing on his notion of the name, shows its theological origin and its epistemological and ontological repercussions. The relationship between concrete thought and abstract thought is shown.

Keywords: Name. Original sin. Revelation. Translation. Judgment. Benjamin. 
Existe en el animal humano la imperiosa necesidad de darle sentido a todo objeto, fenómeno, suceso o actitud que acontezca en el universo, este pude ser muy limitado o basto, pero cada hecho debe estar en un todo ordenado. El desorden nos causa inquietud, sea que un objeto este fuera de lugar, emerja un hecho o una actitud no sea la apropiada para que entremos en zozobra, incluso el caos o desorden debe tener un sentido cuando acontece. El determinismo es una postura que nos puede servir de ejemplo, procura explicar la causa de cada hecho o fenómeno, saber por qué sucedió o por qué no sucedió, es de vital importancia, quizás porque de ello depende nuestra sobrevivencia. La libertad humana nos causa asombro y nos inquieta, porque introduce lo nuevo, lo inesperado, sea para bien o para mal. Un rasgo de los estudiosos de la filosofía es estudiar a pensadores o corrientes del pensamiento que suponen guardan una visión más coherente o consistente, que tiene la capacidad de ordenar lo que a nuestra perspectiva aparece como caótico. No es extraño entonces que acudamos a pensadores cuya visión sobre el mundo y el hombre guarde mayor consistencia con el fin de recuperar algo para nuestra propia perspectiva.

Benjamín se ha convertido en los últimos años en referencia para quienes están cansados y buscan nuevas formas de expresión, acusan a la filosofía dominante de establecer un estilo narrativo ajeno a la libertad creativa, el texto científico lo sienten limitado y no adecuado para expresar las nuevas ideas, requieren esa libertad que da el ensayo y consideran que un ejemplo de este tipo de escrito les ayudará a comunicar mejor sus pensamientos (Cfr: Forster, 2011, pp. 13-25). Otros, lo consideran un innovador de las posturas de izquierda, al retomar su pensamiento encuentran asideros para elevar agudas críticas al capitalismo, incluso hay quien lo considera como una renovación del marxismo.

En los últimos 150 años se ha considerado el lenguaje como la fuente de los problemas más acuciantes, entre mundo y consciencia su mediación se ha vuelto compleja y problemática. No es que hasta ese momento se haya reflexionado sobre el lenguaje, sino que se convirtió a fines del siglo XIX en un obstáculo y facilitador para pensar y nombrar la realidad. Los problemas epistemológicos y ontológicos adquirieron una dimensión que antes estaba oculta. 
Walter Benjamín nació en Berlín en el año de 1892 y se suicidó en 1940, en la frontera francesa con España, al tratar de cruzarla para llegar a Lisboa, donde abordaría un barco rumbo a EEUU y, con ello, liberarse del tormento nacionalsocialista. Sus problemas de salud le impidieron realizar un segundo intento, absolutamente fatigado y con las tropas alemanas ingresando a Francia decidió quitarse la vida con una sobre dosis de morfina en Port Bou (Cfr: Luelmo, 2009).

Pensador de origen judío, cuya familia estaba asimilada a la cultura occidental y en particular a la alemana, con la publicación de sus diferentes escritos queda cada vez más clara este ensamble de las dos tradiciones. Ser un judío asimilado, cuyas previas generaciones estaban distantes de sus tradiciones y buscaban incorporarse a un mundo laico, ajeno aquello que todavía los caracterizaba en el mundo, tuvo un fuerte impacto en su pensamiento.

Gershon Scholem nos ha dado un retrato del drama que atravesaron los jóvenes judíos que vivieron antes y durante de la primera guerra mundial en Alemania, el deseo de algunos por mostrarse más alemanes que los alemanes, el de los otros, por recuperar sus raíces judías. En este entramado se ubica y precisa la actitud que tuvieron él y Benjamín. No es extraño que ambos corrieran por senderos diferentes y que a su vez quedaran altamente enlazados; uno fue a Palestina, el otro se quedó en Alemania (Cfr: Scholem, 2014).

Hombre profundamente religioso, con actitud mística, que se refleja en sus diferentes textos envueltos por un impulso mesiánico. En 1916 escribió un texto titulado: Sobre el lenguaje general y sobre el lenguaje de los hombres ${ }^{1}$, que es ejemplo de ello. La concepción judía del lenguaje, impregnada de la religiosidad mística, será la constante a lo largo de su vida y su producción intelectual. La importancia de este texto lo muestra Miguel Vedda, en la introducción que escribe para Origen del Trauerspiel Alemán (Benjamín, 2012), considera el relato narrado en la Biblia sobre la creación del hombre y el mundo como fundamental para esclarecer el problema del

\footnotetext{
${ }^{1}$ Hay cuatro versiones en español del texto: Benjamín, W. (2001): Para una crítica de la violencia; Madrid; editorial Taurus; Trad.: Roberto Blatt. (Páginas: 59-74); Benjamín, W. (2007): Conceptos de filosofía de la historia; Buenos Aires: ed. Terramar; Trad.: H. A. Murena y D. J. Vogelmann. (Páginas: 91-108); Benjamín, W. (2010): Obras, Libro II/vol. I; Madrid; Abada editores; Trad.: Jorge Navarro Pérez. (Páginas: 144-162); y Benjamín, W. (1986): Sobre el programa de la filosofía futura y otros ensayos; México D. F.; Editorial Artemisa (Planeta de Agostini S. A.); Trad.: Roberto J. Vernengo (Páginas: 139-153).
} 
lenguaje: "La Biblia, en la medida en que se le considera como revelación, debe necesariamente desarrollar los hechos lingüísticos elementales" (Benjamín, 1986, p. 145). Cuando Ricardo Forster comenta este texto de Benjamín, lo relación con la tradición mística de la cábala y el Zohar, en este sentido es un pensador que se mueve en el dominio de la tradición judía (Cfr: Forster, 2014, pp. 211-238). Puede leerse la definición que da Gershom Scholem de místico en el primero capítulo de su libro: La cábala y su simbolismo (Scholem, 2008, pp. 4-34), en donde atribuye al místico la intención de recuperar la tradición y en su paso, y en buena medida sin intención, revolucionarla; al alterar su naturaleza se da una ruptura:

Las categorías psicológicas no corresponden en absoluto a las categorías históricas. Con mucha frecuencia los místicos han realizado grandes esfuerzos por sostener sus concepciones dentro de marco de la autoridad trasmitida, y sólo fueron llevados a un conflicto declarado con la autoridad constituida porque tuvieron que enfrentarse a una oposición especialmente reacia dentro de su comunidad, la cual les fue imposible superar. Pero si hubiera dependido de ellos, habrían evitado un conflicto que no trataban de buscar. En muchos casos puede probarse que comenzaron a interpretar sus concepciones de una manera cada vez más radical, cuando dicho conflicto les fue impuesto absolutamente en contra de su voluntad (Scholem, 2008, p. 25).

El místico esta en tensión con la tradición, busca recuperarla, porque se le muestra en decadencia y con ello la altera; trata de recuperar lo más sagrado, lo que tiene mayor vida:

[...] la experiencia mística se condensa en un símbolo -a través del contacto de los hombres con el contacto original de la vida- que contiene en sí mismo la destrucción nihilista de la autoridad. La libertad mesiánica en la salvación y el contenido de la iluminación que concierne a la esencia de esa libertad cristalizada alrededor del símbolo de la vida (Scholem, 2008, p. 31). 
De esta experiencia el místico toma fuerzas para enfrentar la tradición y procurar un cambio que retorne la existencia a la tradición. En este sentido Benjamín es un místico que quiere volver al mundo del paraíso perdido.

Muniz-Huberman ha subrayado de manera general la diferencia entre el pensamiento judío y el derivado de la visión griega, que caracteriza el pensamiento occidental:

Una de las diferencias fundamentales entre la cultura occidental y el judaísmo parte de la palabra palabra. Ômona para los griegos es sinónimo de nombre, mientras que en el hebreo davar no es solo palabra sino también cosa. Esta unión de palabra y cosa, habla y pensamiento, discurso y verdad, nunca existió en la cultura griega. Y de ahí proviene el gran abismo entre ambas culturas. El nombre, según el judaísmo, es el verdadero referente de la cosa, es su rasgo esencial, y no lo contrario, como en el helenismo. Por lo tanto, la palabra nunca será un signo arbitrario, sino que connota acción, suceso, materia, proceso (MunizHuberman, 2012, pp. 60-61).

Es común en la cultura occidental considerar los nombres o signos como arbitrarios, cada objeto o cosa puede ser nombrado de diversas maneras, incluso dejar de usar unos para utilizar otros nombres. Un objeto o cosa no está ligado por ningún lazo con su nombre, solo la arbitraria convención humana. En sentido diferente, en la cultura hebrea, cada cosa tiene un nombre que constituye su naturaleza o esencia, nombre y cosa están ligados por el vínculo que Dios estableció desde el momento de la creación.

La tarea de la filosofía es y ha sido liberarnos del error, descubrir aquellas creencias falsas que nos inducen a realizar acciones que fracasan, a eliminar las concepciones del mundo que nos hacen infelices y que nos motivan a causar daño. Los seres humanos pensamos precariamente, con múltiples fallas y errores que aquejan nuestras intuiciones y razonamientos; cometemos errores y nos gustaría mejorar.

Una de las formas que nos ayuda a cometer el menor número de errores es someter a nuestros conocimientos a un proceso de crítica permanente, es decir, recorrer el camino a su fundamento, a la base, para determinar en donde aconteció la falla. La crítica que Benjamín realiza 
es diferente a la que proponía Kant, el retrotraer los saberes y conocimientos a su base, aquello que es fundamento y condición de todo conocimiento; en él hay que ir a la base ontológica religiosa que determina la concepción del mundo y que a traviesa todo producto cultural. En este sentido el lenguaje se convierte en una prioridad en el pensamiento de Benjamín, incluso que la propia historia, dado que la historia será basada en el problema del lenguaje, desde los primeros tiempos a la actualidad.

Benjamín cree en la existencia de Dios, verdad incuestionada en su pensamiento y punto de partida en sus elaboraciones teóricas, de ahí que su crítica es retrotraer todo discurso y acción ante esta realidad. Para Benjamín el hombre fue creado por Dios de tierra (materia prima) y se le dio vida por el aliento divino, a diferencia, las cosas, cuya creación es producto del verbo divino, no uso algún material equivalente a la tierra (barro), solo están formadas por la palabra que emitió para nombrar a cada una y con ello crearlas. Por ello, las cosas tienen un nombre y un espíritu singular, que está contenido en el nombre que las nombra. Nombre y cosa constituyen una unidad. Adán, el primer hombre, en uno de sus primeros actos fue dar nombre a las cosas, nombrarlas en un segundo momento, uso el nombre que Dios había utilizado para crearlas, no difiere el nombre de aquel que se empleó para hacerlas. Pero el lenguaje adánico no tiene el poder de la palabra de Dios, nombra y no crea, pero al ser idéntico y diferente en su esterilidad creativa no tiene posibilidad de error, la cosa es conocida por su nombre, no falla cuando nombra las cosas. Cada palabra nombra la cosa concreta. La palabra falsa o el nombre erróneo, ausente en este momento, viene después de su expulsión del paraíso, a partir de ese momento es necesario distinguir la palabra verdadera de la falsa, el hombre debe cuidarse del error. El olvido de los nombres que, en un primer momento, les fueron asignadas a las cosas conlleva la necesidad de volverlas a nombrar, el primer impulso que Dios dio al hombre al pedirle que nombrara las cosas y los animales está presente, pero olvidado, quedó sepultado, ajeno a este tercer momento en que el hombre nombra las cosas; ahora los nombres y las cosas son ajenos el uno al otro. El nombre de un objeto es un nombre equivoco y nada detiene al hombre de seguir creando nuevos nombres (Cfr: Benjamín, 1986, pp. 145-147). 
Benjamín subraya el papel central que el lenguaje juega en la vida humana. El lenguaje lo permea todo: "Toda manifestación de la vida espiritual humana puede ser concebida como una especie de lenguaje y esta concepción plantea -como todo método verdadero- múltiples problemas nuevos" (Benjamín, 1986, p. 139). Esta valoración de lenguaje como problema central lo acompañará a lo largo de su producción intelectual y le permitirá plantear viejos problemas bajo nueva luz, así como problemas insospechados. Como comenta Yvars en la presentación del libro de Gershom Scholem Walter Benjamín. Historia de una amistad:

Su concepción del lenguaje, que mantuvo sin decisivas variaciones desde sus inicios de su amistad con Scholem hasta sus últimos escritos, se presenta como una teoría del lenguaje en general, es decir, de todas las cosas, cada una de las cuales poseerá su propia lengua, aun cuando, sin embargo, todas ellas quedaran enlazadas por esa especie de esperanto divino que será la lengua de los hombres. Su punto de partida no era otro que el Génesis, donde el mundo aparece creado por la Palabra de Dios. Benjamín busco con ahínco aquello que él mismo llamaba magia del lenguaje: el poder taumatúrgico de la escritura cuando se ve libre a la inmediatez del puro nombrar, creador y revelador a la par (Scholem, 2014, p. 13).

Su interés por el Surrealismo sobre todo por la embriaguez como factor determínate para la creatividad espontánea y que valoraba más allá de su efecto en el arte, así como la literatura infantil, quizás obedecía a que este tipo de lenguaje le parecía más cercano al que Dios le otorgó a Adán en el paraíso.

Para Benjamín se abre a través del lenguaje una forma de acceder al mundo y las visiones de los hombres: "Lenguaje significa en este contexto el principio encaminado a la comunicación de contenidos espirituales en los objetos en cuestión: en la técnica, en el arte, en la justicia o en la religión" (Benjamín, 1986, p. 139). No le interesa el lenguaje que se usa en las diferentes disciplinas que abordan estos temas, le interesa los problemas que se suscitan en esta dimensión humana y que están relacionados con su concepción del lenguaje.

El hombre se comunica con otro hombre y por esta acción trasmite contenidos espirituales, pero es más que esto, la lengua abarca todo sin excepción y las cosas participa de la lengua y no lo 
piensa metafóricamente, supone que las cosas, al tener un nombre asignado por Dios, participa de la lengua: "No hay acontecimiento o cosa en la naturaleza animada o inanimada que no participe de alguna forma de lengua, pues es esencial a toda costa comunicar su propio contenido espiritual" (Benjamín, 1986, p. 139). Atribuye de una manera extraña un cierto animismo a las cosas, donde cada una de ellas está compuesta del nombre que recibió en el momento de su creación y este sería un determinado contenido espiritual. Cada cosa contiene un contenido espiritual que comunica al hombre.

En un sentido animista supone que cada objeto o cosa es una entidad espiritual, ello porque Dios las creo nombrándolas, el nombre que se les otorgó es la cosa misma. El contenido espiritual es el lenguaje que constituye a la cosa. Ontológicamente existen los nombres que Dios emitió en la creación y que a nuestros ojos se muestran como cosas u objetos. Cuando se le nombra en el lenguaje posadánico, después de la expulsión del paraíso, las cosas están distantes, ajenas al signo que las designa.

Cualquier cosa o animal que no tuviera relación con la lengua adánica no sería una cosa o un animal, sería una representación en la subjetividad, una idea: "Un ser que estuviera enteramente sin relaciones con la lengua es una idea; pero esta idea no resulta fecunda ni siquiera en el ámbito de las ideas que definen, en su contorno, la de Dios" (Benjamín, 1986, p. 139). El Dios de Benjamín es innombrable, incomunicable e indefinible, de ahí que cualquier intento por dar una definición de Él o cualquier definición que se dé es una idea vacía, no corresponde con nada, no hay un ser nombrado por ella; en sentido inverso hay un ser, cuyo nombre el ser humano no sabe y es Dios. El ser humano crea palabras de manera arbitraria, nombres que no corresponde con el lenguaje de las cosas, sin contenido espiritual, pero cada cosa posee un contenido espiritual que está en su nombre. Idea y nombre refieren respectivamente a la representación mental y a la cosa en sí, donde la primera queda reducida a simple conjetura mental que trata de ser el nombre de una cosa. Esta noción de "idea" es de los rasgos que constituyen la visión burguesa de la lengua.

Acontecen dos sucesos, por un lado, está la cosa-nombre, que tiene contenido espiritual, y por otro, el nombre extraño a la cosa, la idea, el nombre convencional, que el hombre ha inventado 
para nombrar la cosa, este último tiene contenido lingüístico. En todo acto lingüístico acontece que coinciden en una expresión el uso de un término como nombre de una cosa, hecho o suceso, en el marco de una lengua específica, por ejemplo digo "silla" para nombrar un objeto que está delante de mí, el nombre que yo aprendí en mi comunidad de hablantes del español es que ese objeto se denomina "silla", pero siguiendo a Benjamín existe un nombre otorgado por Dios a ese objeto que yo no conozco y que además es su esencia o naturaleza, este nombre, se pronuncie o no, hace posible que la silla exista, sin depender que yo la piense o no. Benjamín supone que las diferentes lenguas humanas, no adánicas, conservan un cierto aspecto espiritual de la lengua adánica, de ahí que algunas emisiones podrían estar cerca de este contenido en mayor o menor grado. El contenido espiritual podría ser comunicado en el contenido lingüístico, cuando una expresión comunica el contenido espiritual de la cosa, la cosa se muestra, pero cuando ambos contenidos no coinciden se dice algo falso. La expulsión del paraíso representó el extravío lingüístico que aqueja al hombre; el lenguaje perdió la capacidad de nombrar la cosa.

Una lengua particular tiene un contenido espiritual que le corresponde y que puede comunicar, no es el hablante quien comunica el contenido espiritual de la lengua, es la lengua quien lo hace. En este sentido el contenido espiritual se identifica con el contenido lingüístico en tanto que este comunica aquel. En el caso que en una lengua se pronuncie un enunciado que sea comprobado como verdadero, será porque los nombres contenidos en él refieren las cosas nombradas. Benjamín parte de que cada lengua particular sería una variación de la lengua primigenia, aquella que Adán usa para nombrar por primera vez las cosas y los animales, pero con notables diferencias, los nombres que estas usan ya no corresponden con los nombres que uso Adán. En este sentido afirma: “Cada lengua se comunica consigo misma” (Benjamín, 1986, p. 140). La lengua guarda cierta independencia de los hablantes, se articula como un todo cerrado de nombres, que al ser usados por los hablantes ponen en marcha el mecanismo de la lengua misma. Benjamín nos pone un ejemplo:

El lenguaje de esta lámpara no comunica la lámpara (pues la esencia espiritual de la lámpara, en cuanto comunicable, no es en absoluto la lámpara misma), sino la-lámpara-del-lenguaje, 
la lámpara-de-la-comunicación, la-lámpara-de-la-expresión. Pues así acontece en la lengua: el ser lingüístico de las cosas es su lengua (Benjamín, 1986, pp. 140-141).

La lampara-cosa es distinta de la-lámpara-de-la-expresión, en sentido habitual está el objeto físico, real, frente a la palabra que nombra a dicho objeto. La lengua particular comunica el ser lingüístico de la cosa, en este caso la-lampara-de-la-expresión, no el contenido espiritual de la lámpara-cosa. La distancia que guarda entre el nombre de la lampara, que es depositario del contenido espiritual, con el nombre contenido en una expresión de una lengua particular es que no necesariamente este refiera aquel, depende del contenido espiritual que le corresponde a esta lengua:

[...] lo que en un ser espiritual es comunicable es su lengua. Todo depende de ese "es" (que significa "es inmediatamente") No: aquello que en un ser espiritual es comunicable se manifiesta en la máxima claridad en su lengua, como se ha dicho en forma de transito; pero eso comunicable es la lengua misma (Benjamín, 1986, pp. 140-141).

Aquella primera lengua que comunica contenidos espirituales con sus nombres, solo puedes ser comunicada dentro de ella misma, para Benjamín la lengua sería equivalente a un todo cerrado que se autocontiene. Al ser una variante de la lengua primigenia, cada lengua particular conserva algo de aquellos nombres pronunciados por primera vez $\mathrm{y}$ en ese sentido expresan a través del contenido lingüístico el contenido espiritual de aquellos nombres, ¿En qué grado se hace? No lo sabemos:

Lo "medial", es decir lo inmediato de cada comunicación espiritual, es el problema fundamental de la teoría lingüística, y si se quiere llamar mágica a esta inmediatez, el problema originario de la lengua es su magia. La fórmula bien conocida de la magia del lenguaje envía a otro: a su infinidad. La infinidad está condicionada por la inmediatez (Benjamín, 1986, pp. 140-141).

La magia a la que refiere Benjamín está en el contenido espiritual que tiene la capacidad de ser comunicado en el nombre; el hombre recibe el mensaje de las cosas y puede comunicarlo a otro 
hombre, lo que el mensaje lleva es el contenido espiritual, que en apariencia es contenido lingüístico, es decir, digo "silla" y en la mente de quien escuche y preste atención aparecerá "silla", puedo verificar esto si la persona me acerca la silla que nombré y no se forma en su mente las cuatro letras que constituye la palabra "silla", sino el objeto nombrado, aquel que refiero cuando expreso el nombre; será muy distinto si quiero que mi escucha piense en la palabra "silla" y entonces procurare que en su mente se forme la palabra con su dos silabas y sus cuatro letras. El contenido espiritual estaría en que ambos pensemos y actuemos conforme al objeto referido, sea la silla como objeto o la palabra "silla". A diferencia del objeto que no requiere de nuestra mente y puede subsistir independientemente de ella, la palabra puede parecernos convencional y sujeta a cambios por acuerdo. El ejemplo es no es bueno, pero ayuda a acercar a este punto que es vital para el pensamiento de Benjamín.

Cada lengua particular tiene un contenido espiritual, el español al ser una variante de la lengua primigenia tiene un contenido espiritual que le corresponde, lo mismo otras lenguas. Cuánto le corresponde a cada una, eso no lo sabemos, ahí reside su magia. Más adelante se aborda el tema de traducción que ayudará a comprender esta expresión.

Esta magia corresponde con el espíritu que contiene la lengua y, por ello, con la de los hablantes de esta lengua. La espiritualidad de un humano está determinada por la lengua que habla:

Y no hay dudas de que la expresión, en su entera esencia, sólo puede ser entendida como lenguaje; y por otra parte, para entender a un ser lingüístico es necesario preguntarse siempre de qué ser espiritual es él la expresión inmediata. Es decir que la lengua alemana, por ejemplo, no es precisamente la expresión para todo aquello que nosotros podemos o suponemos poder expresar a través de ella, sino que es la expresión inmediata de lo que ella comunica. Ese "se" es una esencia espiritual (Benjamín, 1986, p. 140).

Benjamín sugiere en este párrafo que cualquier hablante tendrá límites en su capacidad de expresión dados por la lengua en la que habla, debido a que ésta guarda una distancia respecto a la lengua adánica, más adelante dice: 
¿Qué comunica la lengua? La lengua comunica la esencia espiritual que le corresponde. Es fundamental saber que esta esencia espiritual se comunica en la lengua y no a través de la lengua. No hay por lo tanto un sujeto hablante de las lenguas, si con ello se entiende a quien se comunica a través de tales lenguas. El ser espiritual se comunica en y no a través de una lengua: es decir, no es exteriormente idéntico al ser lingüístico. El ser espiritual se identifica con el lingüístico en cuanto es comunicable (Benjamín, 1986, p. 140).

No es el animal humano quien comunica un contenido espiritual a través de la lengua, sino que ésta comunica su contenido espiritual. Esta idea de Benjamín nos conduce que cada lengua está en posesión de un cierto contenido espiritual, quizás podríamos denominar cultura, cada lengua engendra una cultura y cuando el hablante de esta lengua se expresa a través de sus emisiones, expresa su cultura, cierta forma de ver el mundo y darse un lugar en él. La capacidad de expresar contenidos espirituales está determinada y limitada por la lengua, no es lo que el hablante quiera expresar, es lo que la lengua le permite o determina, consciente e inconscientemente, que pode decir.

\footnotetext{
No hay un contenido de la lengua; como comunicación, la lengua comunica un ser espiritual, es decir una comunicabilidad pura y simple. Las diferencias de las lenguas son diferencias de medios (centros), que se distinguen por así decirlo, por su espesor, es decir gradualmente, y ello en el doble sentido del espesor del comunicante (nominante) y del comunicable (nombre) en la comunicación (Benjamín, 1986, p. 144).
}

Por lo dicho arriba y en contraste con este párrafo, el contenido espiritual no es un todo articulado por partes, es una unidad simple; no tiene mezcla, podríamos pensarla como una unidad discreta, sin problemas de bordes o fronteras, no habrá traslapes, se nos muestra pura. Pienso en caso del nombre "silla", cuando la traigo a mi mente debería estar algo tan simple que no requiero ni siquiera la idea de unidad, sólo está ahí, refiriendo el objeto nombrado, en el acontecer de esta forma en la que no hay otro elemento que genere confusión. Lo complejo de esto es que la imaginación representa un obstáculo para poder entender lo que dice Benjamín. El espesor al que 
se refiere, para hablar de las diferencias entre las lenguas, por un lado, la pone al emisor de la comunicación y, por el otro, el nombre, cada lengua dará un peso o cierta ligereza a cada uno respecto a un conjunto de variables que no especifica Benjamín. Más adelante refiere la revelación como un punto nodal para determinar qué tan cerca esta una lengua especifica de la lengua adánica. La embriaguez, que tomó del Surrealismo, así como el lenguaje infantil, nos podrían orientar para saber este sentido de "puro y simple".

Las cosas y los animales al tener nombre comunican su contenido espiritual al hombre, y este al ser usuario de la lengua comunica su contenido espiritual a otros hombres, para ello construye su lengua: "La esencia lingüística del hombre es por lo tanto nombrar las cosas" (Benjamín, 1986, p. 144). Esta fue su primera tarea y sigue siéndolo. Entender esto implica desenmascarar la concepción esencialmente falsa de la lengua, la concepción burguesa de la lengua.

Esta visión falsa supone que el hombre sólo comunica los nombres de las cosas, no su contenido espiritual, no reconoce que las cosas tienen un nombre y que este es su contenido espiritual, separa cosa y nombre, la cosa es lo real y su nombre es lo subjetivo convencional:

Tal teoría dice que el medio de comunicación es la palabra, que su objeto es la cosa y que su destinatario es el hombre. Mientras que la otra teoría no distingue ningún medio, ningún objeto, ningún destinario de la comunicación. Dice: en el nombre el ser espiritual del hombre se comunica con Dios (Benjamín, 1986, p. 142)

Al comunicarse las cosas con el hombre, es decir, trasmitir su contenido espiritual, realmente las cosas y el hombre se comunican con Dios, en el mismo sentido, cuando un hombre trasmite un contenido espiritual a otro hombre quien medía el proceso de comunicación es Dios. Esto significa que quien se comunica con otros, sólo a través de la lengua humana, no adánica, no está en comunicación con Dios.

Para Benjamín la lengua es esencialmente nominativa, está basada en nombres, las otras partes de la lengua están articulas accesoriamente en referencia a ellos: 
El nombre tiene en el campo de la lengua sólo este significado y esta función incomparablemente alta: la de ser la esencia más íntima de la lengua misma. El nombre es aquello a través de lo cual no se comunica ya nada y en lo cual la lengua misma se comunica absolutamente (Benjamín, 1986, p. 142).

Esta primera tarea, asignada al hombre de nombrar las cosas y los animales, determina la unidad básica y esencial de toda lengua: el nombre. El nombre significa en tanto referencializa a la cosa, no hay otra función que el nombrar la cosa, si alguien pregunta por el significado de un nombre sólo basta con mostrar la cosa nombrada. No hay nada más básico y constitutivo de la lengua. Por ello, supone Benjamín que el hombre no se comunica a través de la lengua sino sólo en ella. La lengua humana es un todo cerrado, constituye la comunicación, y por ello la puede regular:

La creación de Dios se completa cuando las cosas reciben su nombre del hombre, de quien en el nombre habla sólo la lengua. Se puede definir el nombre como la lengua de la lengua (con tal de que el genitivo no signifique la relación del medio sino de lo central), y en este sentido ciertamente, puesto que habla en el nombre, el hombre es el sujeto de la lengua y por ello mismo el único. En la designación del hombre como parlante (que es evidentemente, por ejemplo, según la Biblia, el dador de nombres: "toda designación que el hombre pusiera a los seres vivientes, tal fuese su nombre") muchas lenguas encierran en sí este conocimiento metafísico (Benjamín, 1986, p. 143).

A pesar de la diversidad de lenguas, en cada una subsiste esta función denominativa, que en tanto permita comunicar los nombres podrá trasmitir el contenido espiritual del nombre de cada cosa: "La lengua -y en ella un ser espiritual- se expresa puramente sólo cuando habla en el nombre, es decir en la denominación universal" (Benjamín, 1986, p. 143). Cada lengua está más o menos lejana de esta función, hay una gradación que se podría medir porque en ella se dé la revelación.

Para Benjamín debe darse el nexo entre la filosofía del lenguaje y la religión. Cada lengua es una variación de la lengua adánica, en ella subsiste la tarea de nombrar los objetos, casas, hechos, sucesos y conductas que fue la primera tarea encomendada por Dios a Adán. El hombre distante de 
aquel momento también nombra, cumple que esa responsabilidad, pero hay grados de diferencia entre las acciones llevadas a cabo para nombrar:

Esta gradación, que tiene lugar en la interioridad del ser espiritual mismo, no puede ser colocada bajo ninguna categoría superior y conduce por consiguiente a la gradación de todos los seres espirituales y lingüísticos en grados existenciales u ontológicos, tal como era familiar en la escolástica respecto a los seres vivos (Benjamín, 1986: 144).

Más adelante afirma:

[...] cuanto más profundo, es decir, cuanto más existente y más real es el espíritu, tanto más expresable y expresado resulta; es precisamente, en el sentido de esa equiparación, hacer la relación entre el espíritu y la lengua la relación unívoca por definición, por lo cual la expresión lingüística más existente, es decir más fijada, lo que es lingüísticamente más incisivo e inamovible o, en una palabra, lo más expresado, es a la vez lo espiritual puro. Pero justamente es significa el concepto de revelación [...] (144).

Cada lengua al usar nombres guarda una relación con la lengua adánica, que cuando más se expresa adecuadamente con ellos aquella, más revela el orden divino, más cerca está de ésta. La lengua natural es imperfecta y para ella las cosas son mudas. Para Benjamín las cosas se comunican entre ellas a través de un medio material. En cambio, en el lenguaje humano la comunicación es inmaterial y por ello es espiritual, de ahí la necesidad de usar sonido y símbolos. El aliento que Dios puso en el hombre es vida, espíritu y lengua.

Al ser usada por Dios para crear las cosas y otorgada a Adán para nombrarlas, dice Benjamín: "La lengua es entonces la esencia espiritual de las cosas" (Benjamín, 1986, p. 143). Las cosas son esencia espiritual del lenguaje divino.

Considerando el lenguaje humano y los nombres, debemos subrayar que ha acontecido dos hechos revelados en la Biblia, primero el lenguaje otorgado a Adán pierde toda capacidad de creación y, en segundo término, el lenguaje posadánico ya no posee los nombres que corresponden a las cosas y, por ello, el hombre ya no está en posesión de su conocimiento: 
La más profunda imagen de esta palabra es el punto en el que cual la lengua humana realiza la más íntima participación con la infinitud divina del simple verbo, el punto en el cual no es palabra finita y en la cual no puede producirse conocimiento: en el nombre humano. La teoría del nombre propio es la teoría de los límites de la lengua finita respecto de aquella infinitud. De todos los seres el hombre es quien nombra él mismo a sus semejantes, así como es a quien Dios no ha nombrado (Benjamín, 1986: 147).

Y más adelante dice: “Con la asignación del nombre, los progenitores consagran sus hijos a Dios... El nombre propio es la comunidad del hombre con la palabra creadora de Dios" (147).

El nombre se manifiesta como cosa, conocimiento y comunidad. En tanto el nombre divino es la cosa misma éste constituye su realidad y, por lo tanto, su ser objeto; y el lenguaje adánico nombra la cosa y su nombre es conocimiento porque con ello se muestra la naturaleza de cosa y, finalmente, al ser el animal humano un ser sin nombre y otorgar a sus semenjantes su nombre, con ello confirma el sentido de comunidad, donde unos se reconocen con los otros a través de sus nombres, dada la tarea primordial que Dios le otorgo al hombre. Pero esto se ha perdido y la cosa ya no es nombrada con el nombre que le da el humano, hay un divorcio entre cosa y nombre. El hombre enfrenta un mundo de cosas cuya naturaleza desconoce, a su mirada sólo aparecen fenómenos, apariencias, viles fantasmas que recuerdan lo que no está ahí; pero aún podríamos pensar que tras ese rastro hay algo: "[...] el nombre que el hombre da a la cosa depende de la forma en que la cosa se comunica con él" (Benjamín, 1986, p. 148), según Benjamín, las cosas comunican al hombre su contenido espiritual, el problema es cómo el hombre traduce ese contenido espiritual a lenguaje humano y agrega:

El concepto de traducción conquista su pleno significado cuando se comprende que toda la lengua superior (con excepción de la palabra de Dios) puede ser considerada como traducción de todas las lenguas. Mediante dicha relación de las lenguas como centros de espesor diverso se produce también la traducibilidad de una lengua a otra mediante una continuidad de transformaciones. La traducción rige espacios continuos de transformación y no abstractas regiones de igualdad y semejanza. La traducción de las cosas a la lengua de los 
hombres no es solo traducción de la mudo a lo sonoro, es la traducción de aquello que no tiene nombre al nombre. Es por tanto la traducción de una lengua imperfecta a una lengua más perfecta, y no puede menos que añadir algo, es decir, conocimiento. Pero la objetividad de esta traducción tiene su garantía en Dios (Benjamín, 1986, p. 148).

El conjunto de lenguas que los hombres hablan tendría un prototipo de lengua que consistiría en aquella que garantice una mayor objetividad a sus expresiones, aquella que brinde mayor certeza de verdad a sus oraciones. La traducción mostraría que hay dicho fondo que garantiza el conocimiento objetivo. Por ello las traducciones no son simples equivalencias basadas en la convención, sino un proceso de transformación en la propia lengua para garantizar que los nombres realmente nombren a las cosas referidas. Esa lengua prototipo sería la lengua adánica:

Al acoger la lengua muda y sin nombre de las cosas y al traducirla a los sonidos del nombre, el hombre cumple tal tarea. Esta tarea sería insoluble si la lengua de nombres del hombre y aquella sin nombre de las cosas no estuvieran emparentadas en Dios, emitidas por el mismo verbo creador, que se ha convertido, en las cosas, en comunicación de la materia en mágica afinidad, y, en el hombre, en lengua de conocer y del nombre en espíritu bienaventurado (Benjamin, 1986, p. 148).

Reyes Mate ha comentado la tarea actual para el filósofo respecto a la traducción planteada por Benjamín:

El objetivo del traductor es la "reconstrucción del lenguaje puro". Esto no concuerda con lo que habitualmente entendemos por traducción: hacer comprensible un texto escrito en una lengua que no conocemos. Nadie habla o escribe en la "lengua pura" aunque el traductor se empeñe en decir que "haberla hyala". Existe, sí, pero en exilio, refugiada en la lengua que se traduce (Reyes Mates, 1999, p. 68).

Podríamos pensar en el sentido de la otra lengua. Pero el sentido está más allá, se escapa, porque está ligado al genio de la otra lengua. Cada lengua, según Reyes Mate, tiene un genio que está 
encerrado en forma específica en ella, no puede transformarse en el genio de otra lengua. Se pregunta: “Entonces ¿Qué busca la traducción? Y se responde: Acerarse al lenguaje originario y, por tanto, descubrir lo que es común en el movimiento lingüístico. Ese viaje al origen no le puede realizar un hombre sólo ni una sola traducción lingüística". Ante esta tarea imposible le atribuye a Benjamín una estrategia:

Es evidente que la tarea del traductor se ubica en las palabras, frases, giros con que cada lengua expresa su realidad aludida. Ahora bien, como no hay manera de traducir el genio de cada lengua -encarnado en el modo de decir- lo que le queda al traductor son las palabras. Traducir palabra a palabra, respetando la sintaxis originaria (Reyes Mates, 1999, p. 69).

Este procedimiento sería algebraico, una combinatoria, como la usada por los cabalistas con las letras y palabras de la Tora, partir de la estructura sintáctica de cada palabra he ir al encuentro de la raíz que hace posible la existencia de cada una, el resultado buscado es encontrar lo común a ambas, se podría descubrir que una es la base de la otra. Al usar Adán el lenguaje otorgado por Dios en cada lengua debe existe ocultamente las raíces de esa lengua divina.

Una confusión estaría en tomar una idea por un nombre:

Mediante la palabra el hombre se halla unido a la lengua de las cosas. La palabra humana es el nombre de las cosas. Así no se puede plantear más la idea, que corresponde a la concepción burguesa de la lengua, de que la palabra corresponde a la cosa causalmente, de que constituya un signo de las cosas (o de su conocimiento) puesto por una determinada convención. La lengua no brinda jamás puros signos (Benjamín, 1986, p. 147).

Benjamín presta atención especial al momento de la caída, cuando Adán fue seducido y, por ello, perdió el paraíso. Dios creo el universo nombrando cada una las cosas que lo constituye, esta palabra creadora no fue usada con Adán, él fue hecho de barro (tierra) y luego el creador soplo sobre él, el aliento divino dio vida a Adán y, con ello, su capacidad verbal. Luego, Dios pidió a Adán que nombrara todas las cosas, cada cosa recibió su nombre y se mostró satisfecha con él: 
Que la lengua del paraíso era perfectamente conocedora es algo que no puede ocultar ni siquiera la presencia del árbol del conocimiento. Sus frutos debían dar el conocimiento de lo que es bueno y de lo que es malo. Pero Dios ya había conocido en el séptimo día con las palabras de la creación: "Y he aquí que era muy bueno". El conocimiento que da la serpiente con su seducción, el saber de lo que es bien y mal, carece de nombre. El saber del bien y el mal abandona el nombre, es un conocimiento extrínseco, la imitación improductiva del verbo creador. El nombre sale de sí mismo en este conocimiento: El pecado original es el acto de nacimiento de la palabra humana, en la cual el nombre no vive ya más intacto; es la palabra que ha salido de la lengua nominal, conocedora y, casi se podría decir, que ha salido de la propia magia inmanente para convertirse en expresamente magia. La palabra debe comunicar algo (fuera de sí misma). Tal es el verdadero pecado original del espíritu lingüístico (Benjamín, 1986, p. 151).

Todo lo que existía en el paraíso tenía nombre y Adán lo nombraba por su nombre, cuando Adán quiere que su lengua sea creadora como la de Dios, inventa nuevos nombres a los que ya no corresponde nada, resignifica las cosas y, con ello, confunde los nombres de las cosas con los vacíos términos inventados por él. Esta confusión es lo que Benjamín, siguiendo la tradición judía, llama pecado original. El lenguaje introducido por la serpiente es idéntico a la concepción burguesa de la lengua.

Sin duda, para la palabra que juzga, el conocimiento del bien y el mal es inmediato. Su magia es diversa de la del nombre, pero es igualmente magia. Esta palabra que juzga expulsa a los primeros hombres del Paraíso; ellos mismos lo han provocado según una eterna ley por la cual esta palabra juzgadora castiga -y espera- que la provoquen como única y más profunda culpa (Benjamín, 1986, p. 150).

Siguiendo a Kierkegaard Ilama al hombre que juzga "charlatan", aquel que pronuncia juicios sin poseer el nombre de las cosas. Las consecuencias de esto es que el hombre hace del lenguaje un medio, reduciéndolo a simples señales o símbolos; en ese sentido, surge el juicio, que al no saber que son las cosas el hombre emite juicios sobre ellas; la abstracción es el tercer elemento, esta 
capacidad para pensar de manera universal y general el mundo. El pensamiento burgués se caracteriza por considerar el lenguaje como un conjunto de símbolos, que articulados constituyen juicios y la potencia que otorga a la abstracción. Benjamín opondrá lo concreto de la lengua primigenia con lo abstracto de la lengua humana. Si cada cosa recibió un nombre ese nombre es el nombre propio de la cosa, no pueden existir dos cosas con el mismo nombre, cada una tendrá su propio nombre:

Pero el nombre, en la lengua existente es el terreno, en el cual tienen sus raíces, sus elementos concretos. Pero los elementos abstractos de la lengua -como se puede tal vez suponer- tienen sus raíces en la palabra juzgadora, en el juicio. La inmediatez (es decir, la raíz lingüística) de la comunicabilidad de la abstracción está radicada en el veredicto juzgador y no en lo concreto de las cosas y sus nombres propios. Esta inmediatez en la comunicación de la abstracción ha tomado la forma del juicio cuando el hombre abandono en la caída, la inmediatez en la comunicación de lo concreto, del nombre, y cayó en el abismo de la mediatización de toda comunicación de la palabra como medio, de la palabra vana, en el abismo de la charla (Benjamín, 1986, p. 151).

El lenguaje de Dios es un lenguaje de nombres propios, cada cosa tiene un nombre exclusivamente, no hay dos nombres para una cosa, solo uno:

Las cosas no tienen nombres propios más que en Dios. Pues Dios las ha evocado en el verbo creador con sus nombres propios. Pero en la lengua de los hombres las cosas son superdenominadas (Benjamín, 1986, p. 152).

La pregunta se originó en la charla sobre el bien y el mal. Esta actitud de formular interrogaciones tuvo su aparición en el momento que aconteció el pecado original. El árbol del bien y el mal estaba en el paraíso como emblema del juicio sobre la interrogación, al no existir nombres sin su objeto o referencia no podría haber preguntas o dudas. Acontecido el pecado, con ello dio pie a que los nombres generará duda e inquietud en el usuario: "Está grandiosa ironía es la marca del origen místico del derecho" (Benjamín, 1986, p. 152). 
El derecho, como saber humano, tiene su legitimidad al desconocer lo que sucede o acontece y hay que deliberar y juzgar:

Los signos deben confundirse donde las cosas se complican. Al sometimiento de la lengua a la charla sigue el sometimiento de las cosas a la locura, casi como una consecuencia inevitable (Benjamín, 1986, p. 152).

Este caos introducido por el uso de nombres vacíos provoca que el hablante sospeche de la veracidad de sus propios pensamientos. El ser juzgado implica un proceso de deliberación sobre los hechos ocurridos para poder determinar la culpabilidad.

La perspectiva de Benjamín sobre la naturaleza parte de un cierto animismo que otorga a las cosas, un nivel de conciencia dada su naturaleza espiritual. Asumen que Dios creo las cosas nombrándolas y pido a Adán que les diera un nombre, al caer en pecado ese nombre se olvidó y el hombre tuvo que darles uno artificial. De origen, la naturaleza es muda y noble, todos los seres nombrados por Adán obedecen su palabra. Benjamín, siguiendo la Biblia, supone que la mudes de las cosas las pone en estado de tristeza:

Pero tras la caída, con la palabra de Dios que maldice el campo, el respeto a la naturaleza se transforma profundamente. Comienza su otro mutismo, al que aludimos al hablar de la profunda tristeza de la naturaleza. Es una verdad metafísica la que dice que toda la naturaleza se pondría a lamentarse si le fuese dada la palabra... La naturaleza es triste porque es muda... Ser nombrado -incluso cuando quien nombra es un bienaventurado y similar a Dios- sigue siendo quizás un presagio de tristeza (Benjamín, 1986, p. 152).

Tras el pecado, esta tristeza de la naturaleza se agudiza cuando los hombres en las múltiples lenguas no atinan a nombrarla, tenían en su nombre la capacidad de ser escuchadas, cuando Adán las nombraba, pero ahora su silencio es mayor:

En la relación de las lenguas de los hombres con la de las cosas hay algo que se puede definir aproximadamente como "superdenominación" o exceso de denominación: 
superdenominación como último fundamento lingüístico de toda tristeza y (desde el punto de vista de las cosas) de todo enmudecimiento (p. 152).

El lamento de la naturaleza es un clamor por volver al momento en que se les nombraba por su nombre en el paraíso. En la época actual donde el capitalismo, por su alto proceso industrial, destroza y destruye la naturaleza, prolongando a Benjamín podríamos afirmar, que la naturaleza sufre una tristeza más aguda y angustiante.

Las cosas se comunican entre sí en un lenguaje de la materia, en un proceso mágico: “[...] la comunicación de las cosas es sin duda de un género tal de afinidad que abraza al mundo entero como una totalidad indivisa" (Benjamín, 1986, p. 152). La creación es una unidad, desde la materia inerte al hombre, constituye una unidad por el lenguaje que la envuelve y da orden y sentido, ello se altera y cambia por la reiterada actitud del ser humano, divorciado y extrañado del lenguaje que le fe dado por gracia de Dios.

La interacción del humano con la naturaleza tiene un sentido relativamente positivo en el texto. Hay un breve comentario que anticipa su visión del arte. Benjamín supone que los artistas plásticos al transformar la materia en objetos de gran valor entran en ese lenguaje de la materia:

[...] la lengua de la escultura o de la pintura está fundada en ciertas especies de lenguas de las cosas y que se realice en ellas una traducción de la lengua de las cosas a una lengua infinitamente superior y sin embargo quizás aún de la misma esfera. Se trata aquí de lenguas no nominales, no acústicas, de lenguas de la materia, respecto a los que es preciso pensar en la afinidad materia de las cosas en su comunicación (Benjamín, 1986, p. 152).

La naturaleza es consciente de su condición y constituye una unidad, en su actividad artística el hombre debe conocer la naturaleza para darle múltiples formas, en ese sentido Benjamín anticipar la siguiente idea: "Para el conocimiento de las formas artísticas es válida la tentativa de concebirlas a todas como lenguas y de buscar su relación con lenguas naturales" (Benjamín, 1986, p. 152). El caso de la música y el canto de las aves podrían guiar a buscar este lenguaje natural, pero Benjamín está pensando en que la materia inerte se comunica entre sí, en un lenguaje material. 
En este párrafo se resume la visión que Benjamín tiene del mundo determinado por el lenguaje:

La lengua de un ser es el medio por el cual se comunica su ser espiritual. El río ininterrumpido de esta comunicación atraviesa toda naturaleza, desde lo ínfimo existente hasta el hombre y desde este a Dios. El hombre se comunica con Dios mediante el nombre que da a la naturaleza y a sus semejantes (en el nombre propio) y da a la naturaleza el nombre según se halla atravesado la lengua muda y sin nombre, residuo del verbo creador de Dios, que se ha conservado en el hombre como nombre conocedor y -sobre el hombre- como sentencia juzgadora. La lengua puede ser comparada con una consigna secreta que cada puesto trasmite al otro en su propia lengua. Toda lengua superior es traducción de la inferior, hasta que se despliega, en la última claridad, la palabra de Dios, que es la unidad de este movimiento lingüístico (p. 152).

La jerarquía de lo existente depende del orden o niveles de lenguajes: las cosas compuestas de materia tendrán su lenguaje materia, los animales el propio y los hombres el nombre. Todo ello producto de la voluntad divina que formó el mundo por un acto verbal.

Podríamos cerrar este texto haciendo un recuento de lo dicho:

- El lenguaje es el núcleo que articula los problemas que enfrenta el pensamiento actual. Me parece que sobre esto hay consenso en la actualidad.

- Benjamín parte de la concepción judía del lenguaje, donde el nombre y, en específico, el nombre propio es el eje central; pero su concepción del nombre difiere de la habitual del pensamiento occidental y esta diferencia es la que teje la narración del texto.

- La crítica es realizada por Benjamín como el ir a los hechos religiosos del pecado original que muestran el origen del estado actual del problema. Cuando Adán, seducido por la serpiente, quiere imitar a Dios, usando el lenguaje que le fue otorgado, sin la potencia creadora, para crear, este acto de nombrar artificialmente se convierte en el origen del lenguaje vacío, en lenguaje que se manifiesta en la "charla", en la base de la concepción burguesa del lenguaje. 
- El deseo del hombre por conocer está basado en que tras el lenguaje vacío hay un lenguaje prototipo, de origen divino, dado a Adán en el paraíso. Para llegar a él hay que emprender una traducción, pasar del contenido lingüístico del nombre a su contenido espiritual, dar ese salto mágico.

- La magia que trasmite el nombre en su contenido espiritual es inmediata, pura y simple, pero al traducir una lengua a otra, ambas posadánicas, se requiere una operación que Benjamín llama transformación, no por semejanza o similitud, que recupere el contenido espiritual y, por ello, el nombre.

- El hombre en este momento está atrapado en este lenguaje posadánico, en esta concepción burguesa del lenguaje, por ello los elementos que constituyen sus pensamientos son las ideas, conceptos, razonamientos, juicios y abstracción, que están determinados por concebir el lenguaje como un medio.

- La tarea del filósofo es restablecer ese sentido del lenguaje del paraíso, para ello debe aprender a traducir el contenido lingüístico en el contenido espiritual de los nombres. Quizás por ello le interesó vivamente el uso que el surrealismo otorgó a la creatividad espontanea de la embriaguez del lenguaje. Comunicarse en y no a través del lenguaje.

- La naturaleza de las cosas es el contenido espiritual que, en el momento de la creación, Dios les otorgó. El nombre de cada cosa es la cosa misma, la cosa es su nombre. La realidad es el lenguaje de Dios compuesto de nombres propios, no de nombres comunes o abstractos, sólo un nombre para cada cosa. El pensar en este punto es un pensar concreto, no hay géneros ni especies, no hay pensamientos abstractos.

- Adán poseía el conocimiento, sabia los nombres de cada cosa, pero el lenguaje posadánico, producto del pecado original, ya no está en esa posesión, por ello juzga, delibera y genera preguntas.

- La "charla", este lenguaje vacío, es el origen del juzgar, donde reside la culpa del pecado original. El derecho y la justicia emergen al tener el acto de juzgar como su principal 
actividad, son producto de ese lenguaje vació donde los nombres flotan sin el referente que deberían nombrar.

- La tarea asignada al hombre fue dar nombres, entre otros a sus semejantes, por ello una forma de congraciarse con Dios es otorgar un nombre a cada semejante $y$, con ello, formar una comunidad. El nombre de un ser humano debe reflejar su naturaleza espiritual, debe decir quién es, porque con ello participa de la comunidad.

Es difícil seguir a Benjamín y más difícil es compartir sus reflexiones sobre el lenguaje, hay premisas que son imposibles de sostener. Scholem atribuye a los místicos esa capacidad de tratar de recuperar la tradición y, por ello, la revolucionan. Para quienes no somos judíos ni compartimos ningún credo religioso podría tener un aire de novedad lo dicho por Benjamín, pero no deja de ser un intento por conciliar un mundo y la tradición. Su anticapitalismo no es diferente al de muchas tradiciones, ni su angustia y drama es diferentes a quienes viven la desarticulación y el desmoronamiento de sus creencias. Me parece que lo dicho aquí podría tener valor para comprender a un pensador que está entre épocas, en medio de una vorágine que no concluye. La singularidad de su propuesta ilumina los problemas y a su vez nos invita a ingresar a un mundo que en sí tiene aristas que son problemáticas. Lo positivo y valioso será, para quienes estén interesados en estudiar la historia de las ideas, que en buena medida es la historia de nuestros errores y fracasos, de las rutas y caminos que no debemos seguir.

\section{Referencias}

Benjamín, W. (2001): Para una crítica de la violencia; Madrid; editorial Taurus; Trad.: Roberto Blatt. (Páginas: 59-74).

Benjamín, W. (2007): Conceptos de filosofía de la historia; Buenos Aires: ed. Terramar; Trad.: H. A. Murena y D. J. Vogelmann. (Páginas: 91-108)

Benjamín, W. (2010): Obras, Libro II/vol. I; Madrid; Abada editores; Trad.: Jorge Navarro Pérez. (Páginas: 144-162) 
Benjamín, W. (2012): Origen del Trauerspiel Alemán; Buenos Aires; Editorial Gorla; trad.: Carola Pivetta.

Benjamín, W. (1986): Sobre el programa de la filosofía futura y otros ensayos; México D. F.; Editorial Artemisa (Planeta de Agostini S. A.); Trad.: Roberto J. Vernengo (Páginas: 139-153).

Forster, R. (2011): La muerte del héroe. Itinerarios críticos; Buenos Aires; Ariel/Ediciones Paidós.

Forster, R. (2012); Benjamín: Una introducción; Buenos Aires; editorial Quadrat.

Forster, R. (2014): La travesía del abismo. Mal y modernidad en Walter Benjamín; Buenos Aires; Fondo de Cultura Económica.

Luelmo, C. (2009): Unterwegs. Al paso de Walter Benjamín; Madrid; Maia ediciones.

Mates, R. (1999): De Atenas a Jerusalén; Madrid; Ediciones Akal.

Muñiz-Huberman, A. (2012): Las raíces y las ramas. Fuentes y derivaciones de la Cábala hispano hebrea; México D. F.; Fondo de cultura económica.

Scholem, G. (2008): La cábala y su simbolismo, Ciudad de México; Siglo XXI Editores; trad.: José Antonio Pardo.

Scholem, G. (2014): Walter Benjamín. Historia de una amistad; Trad.: J. F. Yvars y Vicente Jorque. 